\title{
Clinical implications of the specialised B cell response to polysaccharide encapsulated pathogens
}

\author{
C G Vinuesa, C de Lucas, M C Cook
}

Box 1: Summary of main points

- Encapsulated bacteria (meningococci, pneumococci, and H influenzae type b) are major causes of respiratory and meningeal infections in infancy worldwide.

- Factors that predispose to recurrent infection with encapsulated organisms reflect the importance of B cell receptor signalling and production of complement fixing, opsonising IgG antibodies for host defence against these pathogens.

- Investigation of patients with recurrent infection with encapsulated bacteria hinges on identification of defects in antibody production (specific B cell defects, hyposplenism) and opsonisation defects (complement deficiency).

- Capsular polysaccharide antigens evoke type 2 thymus independent (TI-2) antibody responses but fail to generate conventional B cell memory.

- Antibody unresponsiveness to TI-2 antigens can be overcome by inducing $T$ cell help for responses to polysaccharide antigens (for example, with conjugate vaccines).

MRC Centre for Immune Regulation, University of Birmingham Medical School, Edgbaston, Birmingham, UK C G Vinuesa

Department of Paediatric Nephrology, Hospital San Rafael,

Madrid, Spain

C de Lucas

Canberra Clinical School, University of Sydney and The Canberra Hospital, Woden, ACT, Australia M C Cook

Correspondence to: Dr Matthew Cook, Canberra Clinical School, University of Sydney, PO Box 11, Woden, ACT, Australia, 2606

Matthew.Cook@act.gov.au

Submitted 23 January 2001 Accepted 6 March 2001
Polysaccharide encapsulated human pathogens include meningococci, pneumococci, and Haemophilus influenzae type $\mathrm{b}$. These bacteria have caused substantial morbidity and mortality in humans since antiquity and are still the third leading cause of death in the world today. ${ }^{1}$ They account for the majority of childhood mortality from lower respiratory tract infections in developing countries, and are responsible for most cases of bacterial meningitis worldwide. Although these bacteria are members of distinct genuses, clinically they share a predilection for causing invasive disease, especially in young children. This review discusses how the clinical features common to these infections, including the shared predispositions, reflect the special immune response to polysaccharides, which occur in encapsulated bacteria (box 1). In particular, production of antibodies is critical for host defence against these organisms. A description of the basic immune response is used to explain the rationale of diagnostic and preventive strategies for patients with increased susceptibility to infections with encapsulated organisms.

\section{Microbiology of encapsulated bacteria}

Polysaccharide capsules confer virulence, in part because they enable bacteria to evade adaptive and specific immune defence mechanisms. ${ }^{2}$ Capsules inhibit phagocytosis, obscure phosphoryl-choline residues in the cell wall from recognition by $\mathrm{C}$ reactive protein, and offer resistance to the lytic action of complement. Capsules also hide immunogenic proteins and lipids present in their outer cell wall, including lipopolysaccharide in Gram negative bacteria such as $H$ influenzae type $\mathrm{b}$ and meningococcus. Thus, production of opsonising antibody towards capsular polysaccharides that fix complement is critical for early host defence against these organisms.

\section{Predisposition to infection with encapsulated bacteria}

(1) SPECIFIC ANTIBODY UNRESPONSIVENESS TO POLYSACCHARIDES

The most significant cause of failure of B cells to respond to encapsulated organisms is young age. Humans are capable of generating antibodies to protein antigens from birth and therefore can respond to most pathogens. However, an ability to make antibodies to polysaccharide antigens does not start to develop until after 2 years of age, and does not reach adult levels until approximately 5 years of age. This period of polysaccharide unresponsiveness during infancy coincides with the peak incidence of invasive infections with encapsulated organisms. The reason for this unresponsiveness is still not known. Several hypotheses have been put forward, including immaturity of B cells, lack of diversity of the neonatal B cell repertoire, absence of $B$ cells with a marginal zone phenotype, lack of a stromal component in the neonatal spleen, or deletion of polysaccharide specific B cells to prevent autoimmunity from recognition of cross reactive neuronal polysaccharide epitopes. ${ }^{3-5}$

While most individuals acquire the capacity to respond to encapsulated organisms during childhood, specific failure to produce antibodies to polysaccharides may persist. Inability to produce antibodies against polysaccharides may occur in the context of primary immunodeficiency disease, including $\mathrm{X}$ linked agammaglobulinaemia, Wiskott-Aldrich syndrome and ataxia telangiectasia, although these conditions are rare (box 2). Recurrent encapsulated bacterial infection may herald the development of common variable immunodeficiency in adults. Finally, isolated failure to produce antipolysaccharide antibodies may persist after infancy as a discrete but poorly understood 


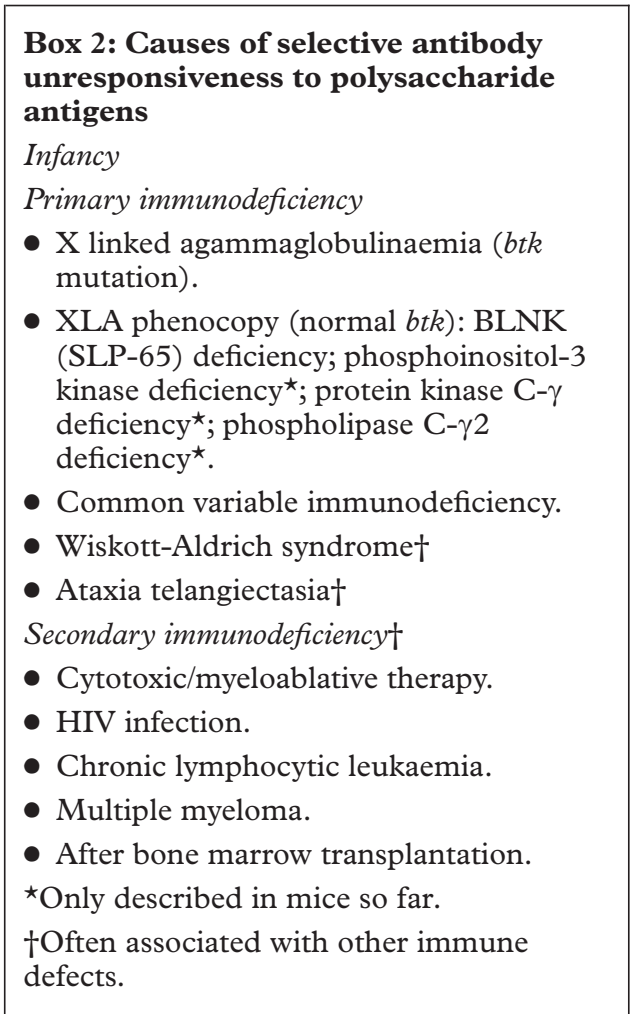

immune defect. This form of immunodeficiency may account for a proportion of adults with normal splenic function and intact complement who present with recurrent infections with encapsulated bacteria.

(2) HYPOSPLENISM

Absence of the spleen increases both the risk of infection with encapsulated organisms and the risk of mortality from invasive disease.$^{67}$ Sepsis in patients with hyposplenism is most commonly caused by pneumococcus, $H$ influenzae type b, meningococcus, and less commonly babesia and Capnocytophaga canimorsus. The incidence of post-splenectomy sepsis is influenced by the indication for the splenectomy, ranging from $1 \%-2 \%$ in trauma patients, up to $10 \%-20 \%$ for B cell activation by polysaccharide antigens patients with Hodgkin's disease or thalassaemia. ${ }^{89}$

\section{(3) COMPLEMENT DEFECTS}

Each pathway of complement activation as well as assembly of the membrane attack complex have been implicated in normal clearance of encapsulated bacteria (fig 1). Defects of the classical complement cascade predispose to infections with encapsulated bacteria, especially pneumococcus because of failure to generate opsonising C3 degradation fragments. ${ }^{10-13}$ Abnormalities that result in excessive C3 consumption and functional $\mathrm{C} 3$ deficiency, such as factor I deficiency or C3 nephritic factor (an autoantibody that may accompany mesangiocapillary glomerulonephritis), predispose to the same spectrum of infections. ${ }^{14}{ }^{15}$ Properdin deficiency, which prevents activation of the alternative pathway, predisposes to recurrent infection and fulminant meningococcaemia. ${ }^{16}$ There is evidence to suggest that some polymorphisms of mannose binding lectin confer an increased risk of meningococcal disease. ${ }^{17}$ Assembly of the membrane attack complex from the late complement components (LCC, C5-9) is particularly important for host resistance to invasive neisserial disease and defects of this complex predispose to meningococcaemia, meningococcal meningitis, and disseminated gonococcal infection, rather than invasive infections with encapsulated organisms per se. ${ }^{18} 19$

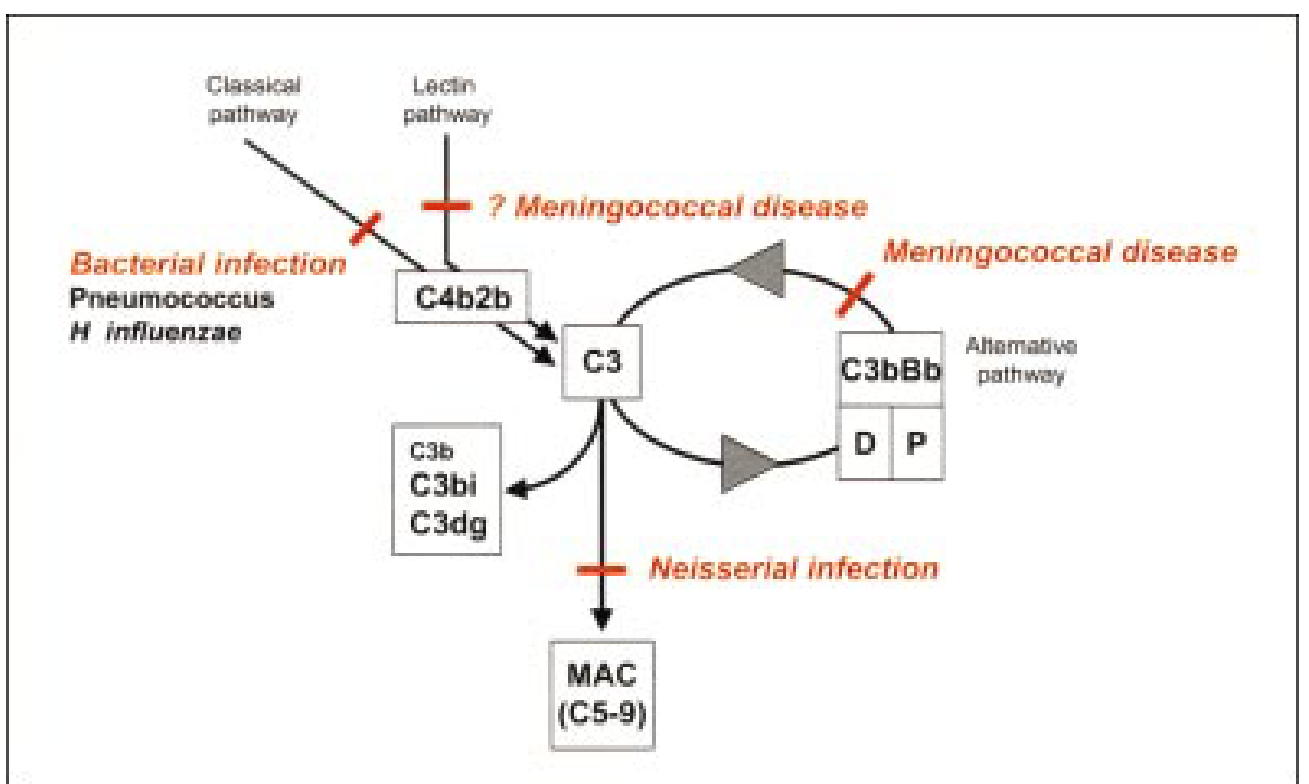

Figure 1 Complement defects and susceptibility to encapsulated bacteria. Summary of the three pathways of complement activation, which generate $C 3$ convertases $(C 4 b 2 b$ and $C 3 b B b)$, opsonising $C 3$ degradation products $(C 3 b i, C 43 d g)$, and the membrane attack complex $(M A C)$. Defects that predispose to infection with encapsulated organisms are indicated $(P=$ properdin; $D=$ factor $D$ ). 


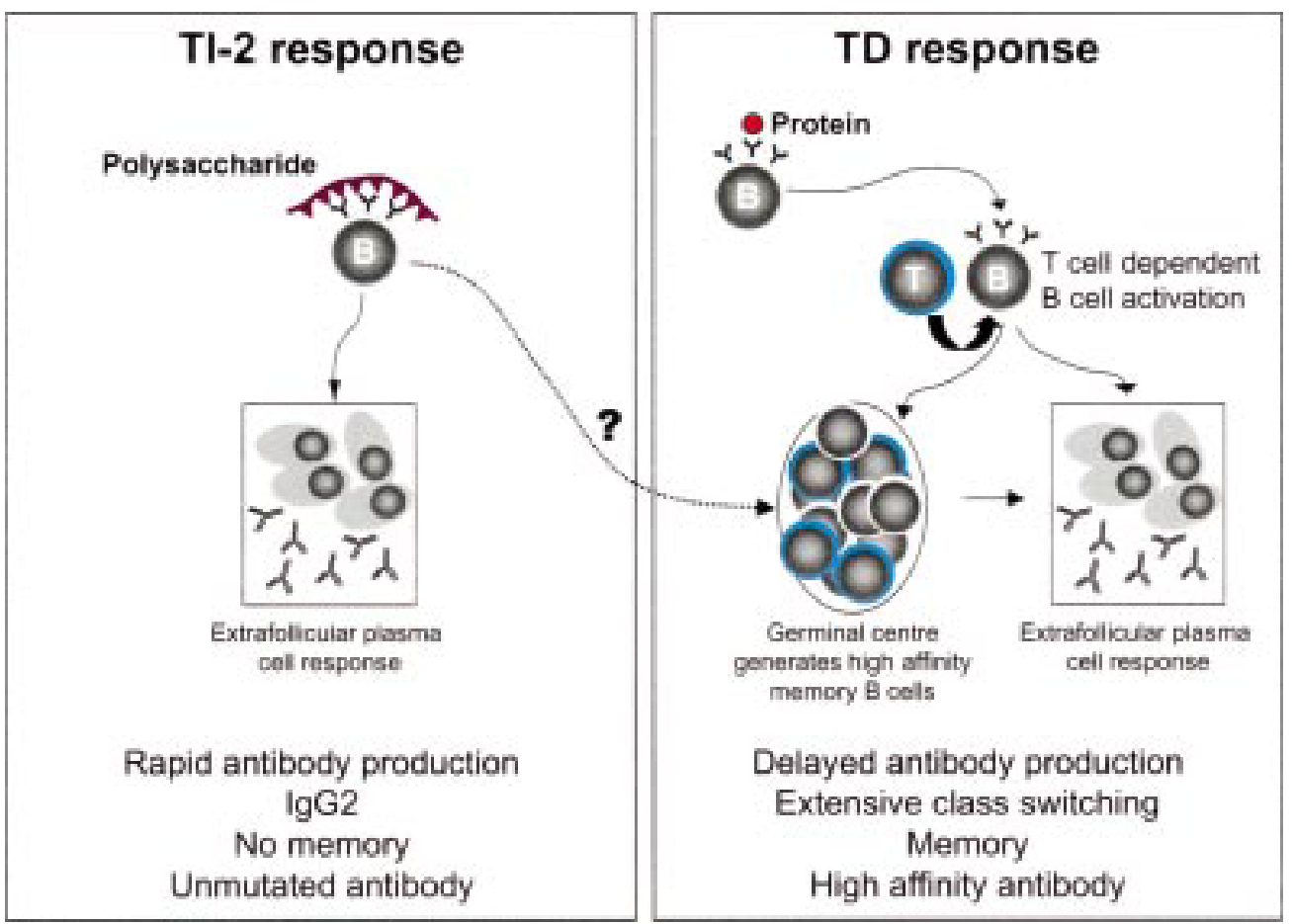

Figure 2 Summary of TI-2 and TD immune responses. Polysaccharide (TI-2) antigens activate B cells in the absence of $T$ cell help (left panel). B cells differentiate into proliferating plasmablasts then antibody secreting plasma cells in extrafollicular areas of the spleen. This leads to rapid antibody production (predominantly IgM, IgG2, and IgG1). Activation of $B$ cells with conventional protein antigens requires $T$ cell help (right panel) and $B$ cells then differentiate into either extrafollicular plasma cells, responsible for early antibody production, or germinal centres, which produce high affinity antibody and memory $B$ cells.

\section{Basic immunology: response to polysaccharides}

(1) B CELL ACTIVATION BY POLYSACCHARIDES Immunologists classify polysaccharides as type-2 thymus independent (TI-2) antigens, whereas lipopolysaccharide (endotoxin) is a TI-1 antigen, and proteins are thymus dependent (TD) antigens (fig 2). The defining characteristics of TI-2 antigens are their high molecular weight, repetitive epitopes, and resistance to degradation in vivo. They cause extensive cross linking of $\mathrm{B}$ cell receptors (BCRs), but they are poorly internalised by $\mathrm{B}$ cells. ${ }^{20}$ The potency and persistence of the signal through BCRs after ligation by TI-2 antigens probably obviates the requirement for $T$ cell help (hence the term "thymus independent"), which in any case is unavailable because B cells do not process and present epitopes from polysaccharides to $\mathrm{T}$ cells. By contrast, conventional or TD protein antigens only induce antibody production after $\mathrm{B}$ cells have received $T$ cell help, which is elicited when $B$ cells process and present peptides to primed $\mathrm{T}$ cells.

$\mathrm{T}$ cell priming takes one to three days and is required before $T$ cells can provide help to $B$ cells for responses to TD antigens. As this is unnecessary in responses to TI-2 antigens, B cell activation and antibody production occurs earlier than in TD B cell responses. ${ }^{21}$ While this rapid antibody response may be crucial for host defence, TI-2 antigens fail to stimulate high affinity memory B cells so repeated exposure to TI-2 antigens does not evoke an anamnestic response. This is because germinal centres, which are the sites of memory B cell formation, are unusual in responses to TI-2 antigens, and when they do form they appear to involute before memory cells are generated. ${ }^{22}$ Nevertheless, TI-2 antigens stimulate a long lived antibody response, probably due to ongoing $\mathrm{B}$ cell activation by persistent polysaccharide antigen. ${ }^{21}$

Classification of polysaccharides as TI-2 antigens originates from the observation that they fail to elicit $\mathrm{B}$ cell responses in the $\mathrm{CBA} / \mathrm{N}$ (X linked immunodeficiency, Xid) strain of inbred mice, which respond normally to both TD and TI- 1 antigens. ${ }^{23}$ The cause of this murine immunodeficiency has been identified as a point mutation in the gene encoding Bruton's tyrosine kinase (Btk). ${ }^{24}$ Btk participates in several signalling pathways downstream from the BCR, which are critical for survival and differentiation of activated $\mathrm{B}$ cells in response to polysaccharide antigens (fig 3). Investigations of Btk signalling pathways have proved informative about susceptibility to encapsulated organisms.

Point mutations of $b t k$ in humans cause $\mathrm{X}$ linked agammaglobulinaemia (XLA), which is characterised by B cell deficiency and low or absent serum immunoglobulin. Interestingly, rare circulating B cells have been isolated from patients with XLA and shown to be selectively unresponsive to TI-2 antigens. ${ }^{25}$ This is consistent with evidence that the bulk of morbidity in XLA is due to respiratory tract infections with encapsulated bacteria. Some viruses have been shown to stimulate TI-2 responses revealing that they are not only evoked by polysaccharides. ${ }^{26}$ For example, enteroviruses 


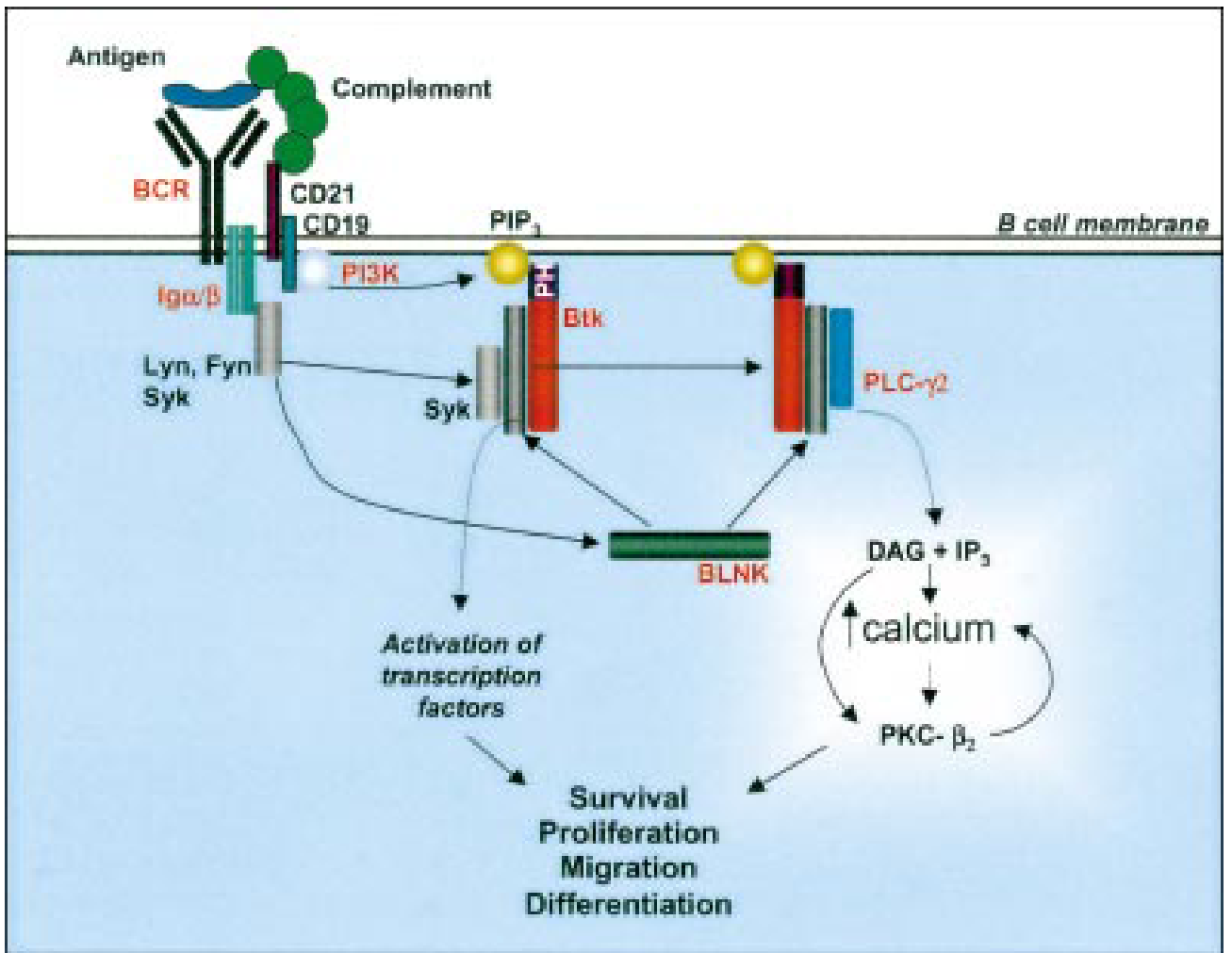

Figure $3 \quad B$ cell signalling pathways and defective responses to TI-2 antigens. Studies in mutant mice and investigation of immunodeficient humans reveal that mutations of Btk, Iga/ $\beta, B L N K$, PI3K, PKC- $\gamma$, and PLC- $\gamma 2$ result in defective responses to TI-2 antigens (indicated in red). The common feature appears to be diminution of calcium fluxes after BCR ligation. Antigen binds to the BCR (membrane bound Ig complexed with Iga and Ig $\beta$ ). Complement coated antigen binds to B cell coreceptors (CD21) to enhance B cell activation. The BCR complex phosphorylates protein tyrosine kinases (Lyn, Fyn, and Syk) and CD19, which then activate phosphoinositol-3 kinase (PI3K). PI3K generates inositol phosphate metabolites including PIP, which binds to the pleckstrin homology (PH) domain of Btk and localises it to the cell membrane. Activated Syk phosphorylates the adaptor molecule BLNK, which enables Btk to be phosphorylated by Syk and PLC- 22 to be activated by Btk. Downstream targets include diacylglycerol (DAG), inositol triphosphate $\left(I P_{3}\right)$, and PKC- $\gamma$, which lead to induction of calcium fluxes. Activated Btk also regulates transcription to influence B cell survival, proliferation, and migration.

stimulate TI-2 responses by virtue of the regular spacing of the epitopes on the viral envelope. Failure to clear enteroviral infections is another characteristic of XLA patients. ${ }^{27} 28$ Early antibody response to all of these pathogens is probably important for prevention of haematogenous spread and infection of the central nervous system and other vital organs.

Recent studies have identified patients presenting as XLA phenocopies but who harbour non-Btk gene defects. For example, patients with mutations in the gene for the linker protein, BLNK, present with clinical features typical of XLA. ${ }^{29}{ }^{30}$ Identification of these defects promises further clarification of the biology of TI-2 responses. Mouse studies have shown that selective TI-2 unresponsiveness also occurs after deletion of phosphoinositol-3 kinase or protein kinase C- $\gamma$ genes (box 2, fig 3). ${ }^{31}$ Interestingly, each of these defects also impinge on Btk signalling pathways. The clinical significance of these findings is that patients with selective susceptibility to encapsulated bacteria may be found with similar signalling defects.

(2) THE IMPORTANCE OF THE SPLEEN AND MARGINAL ZONE B CELLS

The increased risk of infection conferred by hyposplenism reflects the fact that antibody responses to polysaccharides occur more readily in the spleen than lymph nodes. Some studies have suggested that specialised splenic macrophages are crucial for removing antibody coated encapsulated organisms from the blood. However, TI-2 responsiveness is maintained even after depletion of these cells from mice. ${ }^{32}$ By contrast, studies have shown that when mice or rats are rendered selectively deficient of marginal zone $\mathrm{B}$ cells, there is a significant impairment of the response to polysaccharides. $^{33} 34$ Thus, a more plausible explanation for the importance of the spleen is that marginal zone $\mathrm{B}$ cells are necessary during responses to TI-2 antigens. ${ }^{34}{ }^{35}$ Marginal zone B cells comprise about $30 \%$ of human splenic B cells, but are rare in most lymph nodes other than mesenteric lymph nodes. A practical consequence of this is that encapsulated bacterial infection via the nose and throat or through the skin is unlikely to produce a strong antibody response in the draining nodes.

(3) THE IMPORTANCE OF OPSONISATION AND IMMUNOGLOBULIN CLASS SWITCHING

A competent immune response to encapsulated organisms depends not only on production of anticapsular antibodies but also on the interaction of these antibodies with serum complement and opsonic receptors for immunoglobulin and complement fragments on phagocytes. Although natural antibodies, 
which comprise low affinity $\operatorname{IgM}$ and are produced in the absence of immunisation, have been suggested to play a part in responses to encapsulated bacteria, production of anticapsular IgG appears to be more important. This is because phagocytes bear receptors for the Fc portion of IgG molecules (termed Fc $\gamma$ receptors), and these are critical for opsonisation. ${ }^{36}$ Studies using mice with selective deficiencies of secreted IgM (natural antibody) support this concept because they have normal TI-2 responses. ${ }^{37} 38$

After immunisation with polysaccharide, B cells undergo immunoglobulin switch recombination predominantly to IgG2 and IgG1. Much of the total serum IgG2 in healthy individuals is derived from TI-2 responses. The explanation for predominance of IgG2 when switching occurs in the absence of T cell help during responses to polysaccharides remains unclear, since IgG2 antipolysaccharide antibodies are no more effective than other IgG subclasses in protecting against pneumococcal infections. ${ }^{39}$ Furthermore, IgG1 is at least as efficient as IgG2 at opsonisation; conjugate $H$ influenzae type $\mathrm{b}$ vaccine (see below) induces predominantly $\operatorname{IgG1}$, which is protective. Combined genetic deletion of IgG1 and IgG2 appears to be compatible with normal health so IgG3 may also provide protection against encapsulated organisms. ${ }^{40}$ In summary, although IgG2 is the predominant class of immunoglobulin produced in response to polysaccharides, this class of antibody does not appear to be especially effective for TI-2 immune responses.

IgM and IgG1-3 anticapsular antibodies can activate the classical complement pathway. The alternative pathway may be activated by direct contact with bacterial cell wall components, but not after contact with the capsule. ${ }^{41} \mathrm{Com}-$ plement degradation products (C3bi and $\mathrm{C} 3 \mathrm{dg}$ ) enhance antibody opsonisation significantly (fig 1). This is illustrated by the finding that induction of polysaccharide specific antibodies, either by passive transfer of anticapsular IgG, or by polysaccharide immunisation, fails to normalise either protection from encapsulated organisms or phagocytosis when complement deficiency is present. ${ }^{42}$ The clinical implication is that both complement defects and Ig defects predispose to infection with encapsulated organisms.

\section{Applied immunology: diagnosis and prevention}

(A) IDENTIFYING PATIENTS WITH SUSCEPTIBILITY TO INFECTION WITH ENCAPSULATED ORGANISMS Complement fixing IgG antibody formation by marginal zone B cells is crucial for normal host defence against polysaccharide encapsulated organisms. In patients with recurrent infections involving these pathogens, investigations should be directed towards these key mechanisms.

(1) Specific antibody defects and IgG subclass deficiency

Although there have been numerous reports of increased risk of infection with encapsulated bacteria in patients with low levels of IgG2, ${ }^{43} 44$

\section{Box 3: Causes of hyposplenism}

- Congenital asplenia.

- Splenectomy.

- Gastrointestinal disease: coeliac disease, inflammatory bowel disease.

- Autoimmune disease: primary biliary cirrhosis, thyroid disease, rheumatoid arthritis, systemic lupus erythematosus.

- Sickle cell disease.

- Infiltration: amyloid, sarcoid.

- Graft versus host disease.

other studies have shown that IgG2 gene deletions are compatible with normal health. ${ }^{40}$ As discussed above, there is no solid biological explanation of why IgG2 deficiency should predispose to infection. The response generated by conjugate vaccines is predominantly IgG1, which represents compelling evidence against a specific requirement for IgG2. Thus, when IgG2 deficiency occurs in patients with recurrent encapsulated bacterial infections it is probably the result of a fundamental defect in responsiveness to polysaccharide antigens, rather than the cause. It follows that the preferred test for heightened susceptibility to infection with encapsulated bacteria is measurement of the capacity to generate polysaccharide specific antibodies after immunisation with a polysaccharide vaccine such as Pneumovax, rather than measurement of IgG subclass levels.

\section{(2) Complement defects}

Inherited complement defects are rare (combined prevalence of $<0.1 \%)^{10}$ and predisposition to infection (unlike autoimmunity) is only manifest in homozygotes. However, among adults presenting with sporadic meningococcal infection, the prevalence of LCC deficiency is $10 \%-15 \%$. $^{45}$ It is important to identify this subset of patients because they suffer a high rate of recurrent infections. Screening for complement deficiency is by total haemolytic complement $\left(\mathrm{CH}_{50}\right)$ assay. Absent haemolytic activity indicates deficiency of a component of the classical or terminal pathways. Assaying specific serum complement components can identify the precise deficiency. Properdin deficiency, which often leads to fulminant meningococcal disease in infancy, is X linked. ${ }^{46}$ Identification of this defect necessitates a screen for the integrity of the alternative pathway, the so-called $\mathrm{AH}_{50}$.

\section{(3) Hyposplenism}

The presence or possibility of hyposplenism is most often determined by obtaining a history of splenectomy, or of a condition that predisposes to functional hyposplenism (box 3). Congenital asplenia is exceedingly rare. The Hox-11 gene has been shown to control spleen development in mice, although analogous defects have not been identified in asplenic humans. ${ }^{47}$ Furthermore, most cases of human 


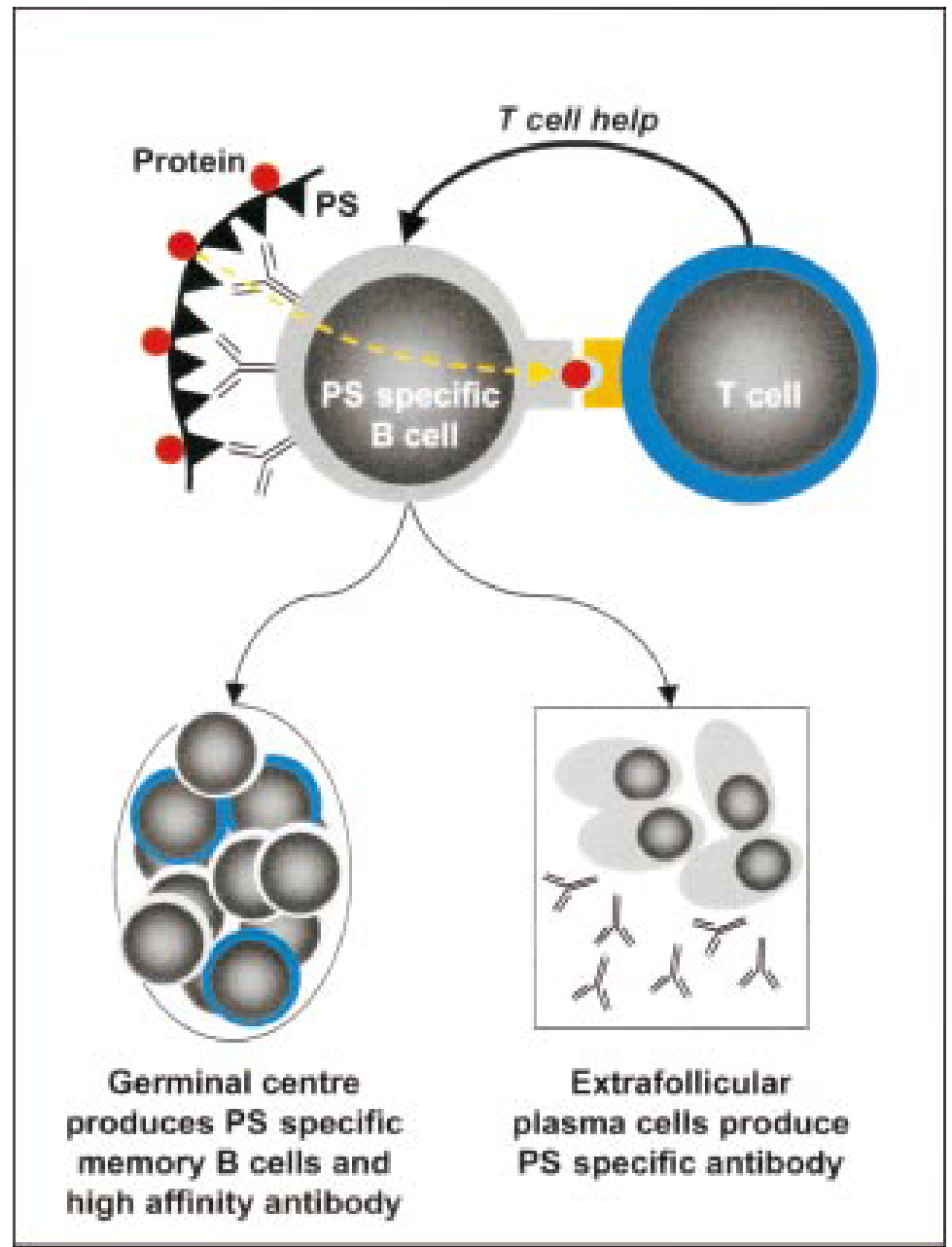

Figure 4 Overcoming TI-2 unresponsiveness with conjugate vaccines. Immunisation with polysaccharide (PS) protein conjugates enables PS specific B cells to attract $T$ cell help. PS specific $B$ cells present protein derived peptides on major histocompatibility complex class II to peptide specific $T$ cells. $T$ cells then provide conventional T cell help (cytokines $+C D 40$ ligation) to the $B$ cell.

asplenia occur in the context of more complicated developmental defects involving abdominal contents, heart, lungs, and face. ${ }^{48}$

The presence of Howell-Jolly bodies, as well as basophilic stippling of the red cells on the blood film usually identifies hyposplenism. Asplenism may be demonstrated by technetium $-99^{\mathrm{m}}$ sulphur colloid scanning because this normally identifies both liver and spleen, whereas only the liver is visualised in the asplenic abdomen.

(B) MANIPULATING THE IMMUNE RESPONSE TO POLYSACCHARIDES

(1) Polysaccharide vaccines

At present, polysaccharide vaccines are the main preventive measures for pneumococcus and group A meningococcus. The 23 valent pneumococcal polysaccharide vaccine (Pneumovax) is recommended for people who are at increased risk of invasive pneumococcal disease. This recommendation cannot apply to infants, who are unresponsive, and the efficacy of this vaccine in certain other high risk groups is questionable. ${ }^{49}$ Evidence that vaccination may actually increase the risk of infection in the elderly and HIV infected individuals is of particular concern. ${ }^{50}$ There is also evidence that a polysaccharide vaccine booster abrogates the benefit of conjugate vaccination. ${ }^{51}$ Together, these findings raise the possibility that polysaccharide vaccination may exhaust the immune response by inducing terminal differentiation to plasma cells of antigen specific cells B cells without replenishing the memory B cell population. Together, these data suggest that conjugate vaccines are preferable for prevention of infections with encapsulated organisms.

\section{(2) Conjugate vaccines}

While there are concerns about the efficacy of polysaccharide vaccines, experience with polysaccharide conjugate vaccines has been spectacularly successful. Conjugate vaccines comprise capsular polysaccharide (for example, $H$ influenzae type $b$ polyribosylribitol phosphate) conjugated with protein (for example, diphtheria toxoid, a non-toxic mutant of diphtheria toxin (CRM197), tetanus toxoid, or the outer membrane protein complex of Neisseria meningitidis). ${ }^{52}$ Consequently, they stimulate TD responses to polysaccharide and are immunogenic for infants (fig 4). The widespread use of conjugated $H$ influenzae type $b$ vaccines has virtually eliminated this disease from developed countries. ${ }^{53}$

Group C meningococcal vaccine was released recently, but a vaccine for group B strains, which account for about $60 \%$ of meningitis in the Western countries, remains elusive. This may be due to a similarity between group B capsular antigen and self antigens in neonatal brain, in which case self reactive $B$ cells would be purged from the neonatal repertoire, precluding responsiveness to vaccine (and pathogen). ${ }^{3}$ As with other encapsulated organisms, meningococcal infections are most common in infancy. However, adolescents are also at risk of fatal invasive meningococcal infection, even though they are immunocompetent. This second peak of incidence correlates with an increased rate of nasal carriage. Conjugate vaccination offers the possibility of reducing disease because long lived, high affinity antibody would be expected to prevent invasive disease, and may also reduce the incidence of nasal carriage. On the other hand, there is also a risk that an effective group $\mathrm{C}$ vaccine may alter meningococcal ecology and increase the prevalence of invasive disease due to group B strains. Production of a conjugate vaccine against pneumococcus has been problematic because there exist over 90 serotypes (that is, $>90$ different polysaccharide capsules). Nevertheless, a heptavalent conjugate vaccine is now available, which theoretically could protect against the majority of invasive disease episodes in young children living in Western countries, ${ }^{54}$ although as with meningococcal vaccination, there is a risk that oligovalent vaccines will result in an increased prevalence of non-vaccine serotypes.

\section{(3) Surrogate T cell help}

Conjugate vaccines demonstrate the value of manipulating the immune system to elicit TD 


\section{Box 4: Future directions}

- Identification of B cell signalling defects other than Btk and BLNK that cause specific unresponsiveness to polysaccharide antigens. Candidate molecules emerging from mouse studies are PI3-kinase, PLC- $\gamma 2$, and PKC- $\gamma$.

- Clarification of the efficacy of polysaccharide vaccines, their indications, and their interactions with conjugate vaccines.

- Expansion of the role of conjugate vaccines including development of an immunogenic type B meningococcal polysaccharide vaccine.

- The H influenzae type b and meningococcus type $b$ genomes, which have been sequenced, may reveal genes encoding highly conserved proteins for use in conjugate vaccines.

responses to polysaccharide antigens. Given the obstacles to making conjugates of all the clinically significant polysaccharides, an alternative strategy is to provide surrogate $\mathrm{T}$ cell help in the form of agonistic anti-CD40 antibody treatment at the time of polysaccharide immunisation. This strategy has been shown to enhance responses to polysaccharide antigens. ${ }^{55}$ Studies in mice sound a note of caution, however, for anti-CD40 antibodies result in substantial splenomegaly associated with massive proliferation of lymphoid and myeloid derived cells, but fail to generate either germinal centres or memory responses when given with TI- 2 antigen. ${ }^{56}$

\section{Summary}

It is difficult to exaggerate the impact of encapsulated bacteria on human health. Our understanding that polysaccharide antigens activate $\mathrm{B}$ cells in a $\mathrm{T}$ independent manner, and that infants are unable to generate TI-2 responses explains the pattern of invasive disease due to these organisms, and has led to successful intervention with conjugate vaccination. Recent developments in B cell biology hold the promise of explaining selective TI-2 unresponsiveness in adults.

Box 4 shows future directions.

MCC is supported by grants from the Sylvia and Charles Viertel Foundation and the University of Sydney. CGV is a recipient of an MRC Clinical Research Fellowship.

1 Murray CJL, Lopez. AD. Alternative projections of mortality and disability by cause 1990-2020: global burden of disease study. Lancet 1997;349:1498-504.

2 Tuomanen E. Molecular and cellular biology of pneumococcal infection. Curr Opin Microbiol 1999;2:35-9.

3 Finne J, Leinonen M, Makela PH. Antigenic similarities between brain components and bacteria causing meningitis. Implications for vaccine development and pathogenesis. Lancet 1983;ii:355-7.

4 Malynn BA, Yancopoulos GD, Barth JE, et al. Biased expression of $\mathrm{J}_{\mathrm{H}}$-proximal $\mathrm{V}_{\mathrm{H}}$ genes occurs in the newly generated repertoire of neonatal and adult mice. $f$ Exp Med 1990;171:843-59.

5 Timens W, Boes A, Rozeboomuiterwijk T, et al. Immaturity of the human splenic marginal zone in infancy-possible contribution to the deficient infant immune response. $\mathscr{f}$ Immunol 1989;143:3200-6.
6 Ferguson A. Hazards of hyposplenism. BMF 1982;285: 1375-6.

7 Amlot PL, Hayes AE. Impaired human antibody response to the thymus independent antigen, DNP-Ficoll, after splenectomy. Implications for post-splenectomy infections. Lancet $1985 ; \mathbf{i}: 1008$

8 Holdsworth RJ, Irving AD, Cuschieri A. Postsplenectomy sepsis and its mortality rate: actual versus perceived risks. $\mathrm{Br}$ f Surg 1991;78:1031-8.

9 Styrt B. Infection associated with asplenia: risks, mechanisms, and prevention. Am f Med 1990;88:33-42.

10 Ross SC, Densen P. Complement deficient states and infection: epidemiology, pathogenesis and consequences of neisserial and other infections in an immune deficiency. Medicine (Baltimore) 1984;63:243-73.

11 Fasano MB, Hamosh A, Winkelstein JA. Recurrent systemic bacterial infections in C2 deficiency. Pediatr Allergy Immunol 1990;1:46-9.

12 Ekdahl K, Truedsson L, Sjoholm AG, et al. Complement analysis in adult patients with a history of bacteremic pneumococcal infections or recurrent pneumonia. Scand $\mathcal{F}$ Infect Dis 1995;27:111-17

13 Bishof NA, Welch TR, Beischel LS. C4B deficiency: a risk factor for bacteremia with encapsulated organisms. F Infect Dis 1990;162:248-50.

14 Leitao MF, Vilela MM, Rutz R, et al. Complement factor I deficiency in a family with recurrent infections. Imтилорharmacology 1997;38:207-13.

15 Wahn V, Muller W, Rieger C, et al. Persistently circulating C3 nephritic factor (C3 NeF)-stabilized alternative pathway C3 convertase (C3 CoF) in serum of an 11-year-old girl with meningococcal septicemia-simultaneous occurrence with free C3 NeF. Pediatr Res 1987;22:123-9.

16 Cunliffe NA, Snowden N, Dunbar EM, et al. Recurrent meningococcal septicaemia and properdin deficiency. $\mathcal{F}$ Infect 1995;31:67-8.

17 Hibberd ML, Sumiya M, Summerfield JA, et al. Association of variants of the gene for mannose binding lectin with susceptibility to meningococcal disease. Lancet 1999;353: 1049-53.

18 Petersen BH, Lee TJ, Snyderman R, et al. Neisseria meningitidis and Neisseria gonorrhoea bacteremia associated with C6, C7, or C8 deficiency. Ann Intern Med 1979;90:917-20.

19 Platonov AE, Beloborodov VB, Vershinina IV. Meningococcal disease in patients with late complement component
deficiency: studies in the USSR. Medicine (Baltimore) 1993; 72:374-92.

20 Mond JJ, Lees A, Snapper CM. T cell-independent antigens type 2. Anпu Rev Immunol 1995;13:655-92.

21 García de Vinuesa C, O'Leary P, Sze DM, et al. T-independent type 2 antigens induce $\mathrm{B}$ cell proliferation in multiple splenic sites, but exponential growth is confined to extrafollicular foci. Eur f Immunol 1999;29:1314-23.

22 García de Vinuesa C, Cook MC, Sunners Y, et al. Germinal centres without T cells. F Exp Med 2000;191:485-94.

23 Scher I. CBA/N immune defective mice: evidence for the failure of a B cell subpopulation to be expressed. Immunol Rev 1982;64:117-36

24 Thomas JD, Sideras P, Smith CIE, et al. Colocalization of $\mathrm{X}$-linked agammaglobulinaemia and X-linked immunodeficiency genes. Science 1993;261:355-8.

25 Nonoyama S, Tsukada S, Yamadori $\mathrm{T}$, et al. Functional analysis of peripheral blood B cells in patients with X-linked agammaglobulinemia. F Immunol 1998;161:3925-9.

26 Bachmann MF, Kopf M. The role of B cells in acute and chronic infections. Curr Opin Immunol 1999;11:332-9.

27 McKinney RE, Katz SL, Wilfert CM. Chronic enteroviral meningoencephalitis in agammaglobulinemic patients. Rev meningoencephalitis in ag $1987 ; 9: 334-56$.

28 Rudge P, Webster AD, Revesz T, et al. Encephalomyelitis in Rudge P, Webster AD, Revesz T, et al. Encephalomyelitis in
primary hypogammaglobulinaemia. Brain 1996;119:1-15.

29 Minegishi Y, Rohrer J, Conley ME. Recent progress in the diagnosis and treatment of patients with defects in early B-cell development. Curr Opin Pediatr 1999;11:528-32.

30 Minegishi Y, Rohrer J, Coustan-Smith E, et al. An essential role for BLNK in human B cell development. Science 1999; 286:1954-7.

31 Fruman DA, Satterthwaite AB, Witte ON. Xid-like phenotypes: a B cell signallosome takes shape. Immunity 2000;13:1-3.

32 Kraal G, Ter Hart H, Meelhuizen C, et al. Marginal zone macrophages and their role in the immune response against T-independent type 2 antigens: modulation of the cells with specific antibody. Eur f Immunol 1989;19:675-80.

33 Guinamard R, Okigaki $M$, Schlessinger J, et al. Absence of Guinamard R, Okigaki M, Schlessinger J, et al. Absence of
marginal zone B cells in Pyk-2-deficient mice defines their marginal zone B cells in Pyk-2-deficient mice defines their
role in the humoral response. Nature Immunol 2000;1:31-6.

34 Lane PJL, Gray DS, Oldfield S, et al. Differences in the recruitment of virgin B cells into antibody responses to thymus dependent and thymus independent type- 2 antigens. Eur F Immunol 1986;16:1569-75.

35 Claassen E, Kors N, Dijkstra CD, et al. Marginal zone of the spleen and the development and localisation of specific antibody-forming cells against thymus-independent type-2 antigens. Immunology 1986;57:399-403.

36 Noel GJ, Katz S, Edelson PJ. Complement-mediated early clearance of Haemophilus influenzae type $b$ from blood is independent of serum lytic activity. F Infect Dis 1988;157: 85-9.

37 Boes M, Esau C, Fischer MB, et al. Enhanced B-1 cell development, but impaired IgG antibody responses in mice deficient in secreted IgM. F Immunol 1988;160:4776-87.

38 Ehrenstein MR, O'Keefe TL, Davies SL, et al. Targeted gene disruption reveals a role for natural secretory IgM in
gene 
the maturation of the primary immune response. Proc Natl Acad Sci U S A 1998;95:10089-93.

39 Briles DE, Forman C, Hudak S, et al. The effects of subclass on the ability of anti-phosphocholine antibodies to protect mice from fatal infection with Streptococcus pneumoniae. $\mathcal{F}$ Mol Cell Immunol 1984;1:305-9.

40 Lefranc M, Lefranc G, Rabbitts TH. Inherited deletion of immunoglobulin heavy chain constant region genes in normal human individuals. Nature 1982;300:760-2.

41 Quinn PH, Crosson FJ, Winkelstein JA, et al. Activation of the alternative complement pathway by Haemophilus influthe alternative complement pathway by Haen

42 Biselli R, Casapollo I, D'Amelio R, et al. Antibody response to meningococcal polysaccharides $\mathrm{A}$ and $\mathrm{C}$ in patients with complement defects. Scand $\mathcal{F}$ Immunol 1993;37:644-50.

43 Oxelius V-A, Laurell A-B, Lindquist B, et al. IgG subclasse in selective IgA deficiency: importance of IgG2-IgA deficiency. N Engl f Med 1981;304:1476-7.

44 Schur PH, Borel H, Gelfand EW, et al. Selective gamma-globulin deficiencies in patients with recurrent pyogenic infections. N Engl f Med 1970;283:631-4.

45 Ellison RT, Kohler PF, Curd JG, et al. Prevalence of congenital or acquired complement deficiency in patients with sporadic meningo 308:913-16.

46 Densen P, Weiler JM, Griffiss JM, et al. Familial properdin deficiency and fatal meningococcemia: correction of the bactericidal defect by vaccination. $N$ Engl $\mathscr{F}$ Med 1987;316:922-6.

47 Roberts CW, Shutter JR, Korsmeyer SJ. Hox 11 controls the genesis of the spleen. Nature 1994;368:747-9.
48 Ivermark BI. Implications of agenesis of the spleen on the pathogenesis on conotruncus anomalies in childhood. Acta Paediatr 1955;44(suppl 104):1-110.

49 Fine MJ, Smith MA, Carson CA, et al. Efficacy of pneumococcal vaccination in adults: a meta-analysis of randomized controlled trials. Arch Intern Med 1994;154:2666-77.

50 French N, Nakiyingi J, Carpenter LM, et al. 23-valent pneumococcal polysaccharide vaccine in HIV-1-infected Ugandan adults: double-blind, randomised and placebo controlled trial. Lancet 2000;355:2106-11.

51 MacLennan J, Obaro S, Deeks J, et al. Immune response to revaccination with meningococcal $\mathrm{A}$ and $\mathrm{C}$ polysaccharides in Gambian children following repeated immunisation during early childhood. Vaccine 1999;17:3086-93.

52 Anderson P. Antibody responses to Haemophilus influenzae type $b$ and diphtheria toxin induced by conjugates of oligosaccharides of the type $b$ capsule with the non-toxic protein CRM197. Infect Immun 1983;39:233-8.

53 Hargreaves RM, Slack MPE, Howard AJ, et al. Changing patterns of invasive Haemophilus influenzae disease in Engpatterns of invasive Haemophilus influenzae disease in Eng-
land and Wales after introduction of the Hib vaccination programme. $B M 7$ 1996;312:160-1.

54 Butler JC. Epidemiology of pneumococcal serotypes and Butler JC. Epidemiology of pneumococcal serotypes and conjugate vaccine.

55 Dullforce P, Sutton DC, Heath AW. Enhancement of T cellindependent immune responses in vivo by CD40 antibodies. Nature Med 1998;4:88-91.

56 García de Vinuesa C, MacLennan ICM, et al. Anti-CD40 antibody enhances responses to polysaccharide without mimicking T cell help. Eur f Immunol 1999;29:3216-24.

\section{West Sussex History of Medicine Society}

WSHOMS was formed in 1999 by recognised medical historians to offer a forum of learning in the disciplines of the history of, and ethics in, medicine. This was designed for graduates and students in the healthcare professions and other enthusiasts interested in these topics.

The courses are held annually in the autumn at the Medical Education Centre of St Richard's Hospital in Chichester. Each course is of five Saturday mornings, designed as an introduction to the methodology and techniques of historical research in these areas. Each offers examples of excellence in researching primary and other sources of historical relevanceoften within easy local access and always by those who are recognised as prominent leaders in their fields of study.

The course also provides a step on the path to further study of the history of medicine under the aegis of the Society of Apothecaries by which this is recognised as an appropriate introductory series. The course is accredited for medical CPD, and offers diverse special topics and discussions to meet the interests of all.

Below is the programme for the current course:

15 September: The Royal Defence Medical College-past, present, and future (Col John Richardson) and Unravelling the Web (Hilary Morris)

29 September: Infanticide? An 18th century Westminster Inquisition (Brian Owen-Smith) 20 October: Taking the waters at Tunbridge Wells and Unresearched sources-where is your medical history? (John Ford)

3 November: James Barrie - a remarkable doctor (Ruth Richardson)

17 November: The saga of brucellosis (David Vassalo) and Summing up-have our objectives been met? (Michael Nicholls)

For further information contact The Administrator, Chichester Medical Education Centre, St Richard's Hospital, Spitalfield Lane, Chichester, West Sussex PO19 4SE (tel: 01243 $788122)$. 